\title{
Editorial
}

\section{Firm Size and Sustainable Innovation Management}

\author{
Antonio Messeni Petruzzelli * and Lorenzo Ardito $(\mathbb{D}$ \\ Department of Mechanics, Mathematics \& Management, Polytechnic University of Bari, Via Edoardo Orabona, 4, \\ 70126 Bari, Italy; lorenzo.ardito@poliba.it \\ * Correspondence: antonio.messenipetruzzelli@poliba.it
}

Received: 24 October 2019; Accepted: 30 October 2019; Published: 1 November 2019

check for updates

\begin{abstract}
In this paper, we introduce the themes addressed and the approaches used in the Special Issue "Firm Size and Sustainable Innovation Management" to investigate the relationships between firm size and sustainable innovation management. Specifically, by offering multiple perspectives of analysis, this work increases our comprehension and understanding of the role of firm size for sustainable innovation strategies.
\end{abstract}

Keywords: sustainability; business model; innovation; hospitality; tourism

\section{A Brief Background of the Special Issue}

Interest in the relationship between firm size and innovation management dates back to the pioneering studies by Schumpeter [1]. So far, a wealth of research has been conducted on this topic. However, an in-depth discussion about the influence of firm size on sustainable innovation management has been neglected. That is, in the context of sustainable innovation management, there has been a tendency to rely on the "conventional" theories regarding the role of firm size. However, such theories may be not completely valid in this context because of the specific peculiarities differentiating sustainable innovations from conventional innovations (e.g., regulations, types of firms (e.g., family vs. non-family), ultimate goals, openness, ethics, and more complex innovation outcomes). Therefore, in the realm of sustainable innovation, a reassessment/repositioning of the role of firm size can be reasonable.

Specifically, it has been proven that firm size may directly affect innovation performance or how firms shape their strategic orientations, organizational structure, knowledge management systems, etc. to innovate (e.g., [2-4]). Yet, whether these direct influences of firm size remain the same in the context of sustainable innovation management is still an open area of research. Furthermore, it has been shown that, in some cases, the direct effect of firm size is moderated/mediated by other factors (e.g., absorptive capacity) or, conversely, firm size acts as a moderating/mediating factor in explaining innovation performance (e.g., [5-7]). This implies that the direct effects that firm size has on sustainable innovation management may be subject to some of its specificities. Likewise, the effects of factors already proved to influence sustainable innovation practices, processes, and outcomes, especially if they are contradictory, can be reassessed by distinguishing firms by their size.

All in all, we contend that there are many open issues in the literature regarding firm size and sustainable innovation management. In line with the above debate, this Special Issue contains original contributions that increase our comprehension of this topic.

\section{Form and Contents of the Thematic Issue}

Based on these premises, this special issue adds new knowledge to the existing body of literature on the relationship between firm size and sustainability in innovation processes. Due to the multiple 
potential topics and perspectives related to the role of firm size, papers addressing different research questions and adopting different theoretical lenses and methodologies have been developed.

The Special Issue opens with a paper by Aldieri and Vinci [Contribution 1], who demonstrate that there exists a reduction effect after sustainable innovation, i.e., a reduction in the number of employees to achieve the same production level can result after sustainable innovation, and a compensation effect after sustainable innovation, i.e., an increase in the number of employees produced by the new competitive context, may derive from sustainable innovation, where the compensation effect can be higher than the destruction effect. The data for the analysis are gathered from the R\&D investment scoreboards (2011).

According to the idea that startup firms have the potential to boost innovativeness in today's economy, Cantamessa et al. [Contribution 2] discuss when startups fail. They redirect attention from factors leading to the economic sustainability of startups and focus attention on those factors that, instead, undermine such performance outcome. In detail, by revisiting the SHELL model, originally implemented to classify aviation and both active failures and latent failures caused by the interplay between human and non-human factors (e.g., technological, environmental, and organizational issues), a classification method is proposed to identify startup failures. This classification method has been applied to a sample of 214 startups, for which postmortem reports were available, and suggestions have also been provided for different points of a startup's life. The most relevant reasons for failure, considering different points in time, include lack of business development and the wrong business model, lack of cash and traction, and poor product-market fit.

The paper by Zhang et al. [Contribution 3] seeks to understand how enterprises initiate growth directions and sustain growth management through innovation. Specifically, based on the notion that innovation theories are different between manufacturing and service-dominated industries, such as the construction industry, which is the setting under investigation, this study proposes and adopts quantitative techniques to test a revised framework to identify the levels and priorities of growth management for service innovation, hence explaining how project-based construction organization growth benefits from service innovation. To do so, the nine most widely used innovation theories have been reviewed, and the innovation policy platforms (IPP) proposed by the World Bank Group and the Organisation for Economic Co-operation and Development (OECD) were chosen to synthesize eight key innovation evaluation systems. As a result, it was possible to build new integrated frameworks and indexes for service innovation in the context of the construction industry. In detail, the authors adopted an enterprise growth management model (GMM) using average-score and entropy-weight methods for comparative analysis of development levels of industrial service innovation. Moreover, by relying on the indexes of IPP, a competitive advantage identification method conforming to natural rules to analyze the priorities of development levels was adopted. Eventually, improvement strategies for service innovation to promote growth were proposed.

Shan and An [Contribution 4] delve into the agency problems faced by large firms when addressing investment decisions. That is, agency issues between managers and stakeholders may lead to inefficient investments (e.g., over-investment, under-investment). Stock option incentives appear to reduce agency problems and, hence, are deemed inefficient investments. However, the authors notice that such influence depends on the type of stock option incentives. Thereby, they aim to better assess the relationship between stock option incentive design and inefficient investment, with a particular focus on the role of the individual characteristics of stock option incentives. On the basis of a sample of 511 Chinese companies, it has been shown that incentive-driven stock option incentives reduce inefficient investment, whereas welfare-driven stock option incentives may even increase inefficient investments. These relationships are weakened in state-owned enterprises due to more business limitations and more self-interested managers. It is worth mentioning that evidence suggests that some stock options may be manipulated by managers in the stage of design.

Ze et al. [Contribution 5] redirect the attention to the moderated-mediated relationship between an organization's boundary-spanning search and innovation capability. Data for model testing were 
gathered from 340 valid questionnaires proposed to Chinese firms of different sizes. Results of the study reveal that boundary-spanning search is positively related to innovation capability of enterprises. In detail, boundary-spanning search has a positive impact on the development of network ties, which in turn positively affects innovation capability (i.e., network ties mediate the relationship between boundary-spanning search and innovation capability). Finally, absorptive capacity surprisingly weakens the network ties-innovation capability relationship.

The paper by Chen et al. [Contribution 6] adopts a NK simulation model to simulate the self-organized evolution mechanism of the inner innovation of large-scale construction companies under different contexts. The parameter $\mathrm{N}$ reflects the components of the inner innovation system, while $\mathrm{K}$ is the interaction among them. The NK simulation proposes three modules-ambidexterity, punctuated equilibrium, and automation—as the different contexts that may modify behaviors of the inner innovation system. Findings show that: (a) The higher the $K$, the higher the fitness, regardless of how the relationship strength changes and (b) in the long term, the punctuated equilibrium, ambidexterity, and automation produce the best, moderate, and least performance, respectively, and the punctuated equilibrium mode also guarantees good short-term inner innovation performance.

The paper by Melane-Lavado and Álvarez-Herranz [Contribution 7] assesses what fosters sustainable innovation by using a logit model, analyzing variables of 5897 Spanish companies during the period 2009-2014. Specifically, it is shown that medium and large companies increase a firm's innovative potential. Still, small and medium enterprises (SMEs) will be more innovative if they attain information from universities, internal organizations, and clients or if they cooperate with competitors and universities. In turn, such innovative potential is conducive to enhancing the likelihood of developing sustainable innovations, especially when sustainable goals are set by companies.

Aguilar-Fernández and Otegi-Olaso [Contribution 8] highlight that firms are revising their business models more in light of sustainable development concepts. However, this transition is subject to the peculiar differences between small and large firms, thus suggesting that firms of different sizes face different challenges in this transition process. Therefore, the role of firm size in the change of business models towards sustainable innovation is considered. The analysis was conducted on data from 174 reports available in the Global Reporting Initiative database, using the quantitative content analysis method. The results show that the size of the company influences how the supply chain and the financial elements of the business model are developed. Overall, the larger the company, the more sustainability-oriented approaches can be observed. This is particularly evident in the case of adoption of socio-environmental metrics in the value proposition, the inclusion of responsible suppliers, and the diversion of waste to suppliers (i.e., the back-end development dimensions of business models). Regarding the front-end dimensions, the difference between large and small firms is less evident.

Okwo et al. [Contribution 9] discuss the effect of hedging (i.e., transaction, translation, and economic exposure risk management) on firm survival by considering the mediating effects of firm size and age. Transaction exposure management, translation exposure management, and economic exposure management all positively affect the survival of firms. With regard to the mediating effects of firm size, it only mediates the relationship between economic exposure management and firm survival.

The study by Lee [Contribution 10] examines and finds evidence for the path relationship linking collaboration activities between supply chain organizations (autonomous collaborations and adoption activities), green practices (green activities and green certification programs), and, ultimately, environmental performance. Furthermore, the moderating role of the firm size is considered. Results show that both SMEs and large firms can affect the proposed model, albeit in different ways. Specifically, SMEs present a stronger relationship between adoption activities and green certification programs and green activities. Large firms, instead, lead to a stronger influence of green certification programs and environmental performance. These findings are based on a sample of 218 questionnaires from supply chain firms in South Korea. 
Zada et al. [Contribution 11] examine the effect that small-to-medium-sized forest enterprises (SMFEs) have on the benefits of rural communities and society as a whole. Findings reveal that the existence of SMFEs have a positive and significant impact on a good rural community's livelihood. The results also demonstrate that households engaged in SMFE-related activities earn 3\% more income and possess about $24 \%$ more assets. Several robustness checks confirm these results.

Bahena-Álvarez and Cordón-Pozo [Contribution 12] discuss the role of social entrepreneurs. Through a cluster analysis technique, considering the level of social entrepreneurship intentions reached, they identify four models of organizations that lead SMEs to the development of responsible innovations. The models are (1) the techno-scientific organization, (2) the techno-social organization, (3) the capitalist-social organization, and (4) the capitalist organization. The first two models are more related to entrepreneurial' intentions to pursue innovative and social goals than the last two models, which are mainly driven by economic objectives.

Finally, Lin et al. [Contribution 13] study attempts to conduct a sustainability assessment of Taiwan's semiconductor industry through a new hybrid model using a combined analytic hierarchy process and a two-stage additive network data envelopment analysis. Results demonstrate that Taiwan's semiconductor manufacturing sector has steadily increased its sustainability performance, especially pushed by business growth, which is a function of the number of employees; albeit the main changing trend is due to higher environmental efficiency and not economic efficiency.

Author Contributions: All authors contributed equally to this Editorial.

Funding: This research received no external funding.

Conflicts of Interest: The authors declare no conflict of interest.

List of Contributions:

1. Aldieri, L.; Vinci, C.P. Firm Size and Sustainable Innovation: A Theoretical and Empirical Analysis. Sustainability 2019, 11, 2775.

2. Cantamessa, M.; Gatteschi, V.; Perboli, G.; Rosano, M. Startups' Roads to Failure. Sustainability 2018, 10, 2346.

3. Zhang, J.; Xie, H.; Li, H.; Timothy, R.; Pu, S.; Deng, Q.; Jin, W. Integrated Framework of Growth Management for Identification of Service Innovation Levels and Priorities. Sustainability 2018, 10, 3319.

4. Shan, W.; An, R. Motives of Stock Option Incentive Design, Ownership, and Inefficient Investment. Sustainability 2018, 10, 3484.

5. Ze, R.; Kun, Z.; Boadu, F.; Yu, L. The Effects of Boundary-Spanning Search, Network Ties, and Absorptive Capacity for Innovation: A Moderated Mediation Examination. Sustainability 2018, 10, 3980.

6. Chen, T.; Huang, G.; Olanipekun, O.A. Simulating the Evolution Mechanism of Inner Innovation in Large-Scale Construction Enterprise with an Improved NK Model. Sustainability 2018, 10, 4221.

7. Melane-Lavado, A.; Álvarez-Herranz, A. Different Ways to Access Knowledge for Sustainability-Oriented Innovation. The Effect of Foreign Direct Investment. Sustainability 2018, 10, 4206.

8. Aguilar-Fernández, E.M.; Otegi-Olaso, R.J. Firm Size and the Business Model for Sustainable Innovation. Sustainability 2018, 10, 4785.

9. Okwo, H.; Ezenwakwelu, C.; Igwe, A.; Imhanrenialena, B. Firm Size and Age mediating the Firm Survival-Hedging Effect: Hayes' 3-Way Parallel Approach. Sustainability 2019, 11, 887.

10. Lee, D. Implementation of Collaborative Activities for Sustainable Supply Chain Innovation: An Analysis of the Firm Size Effect. Sustainability 2019, 11, 3026.

11. Zada, M.; Shah, S.J.; Yukun, C.; Rauf, T.; Khan, N.; Shah, S.A.A. Impact of Small-to-Medium Size Forest Enterprises on Rural Livelihood: Evidence from Khyber-Pakhtunkhwa, Pakistan. Sustainability 2019, 11, 2089.

12. Bahena-Álvarez, L.I.; Cordón-Pozo, E.; Delgado-Cruz, A. Social Entrepreneurship in the Conduct of Responsible Innovation: Analysis Cluster in Mexican SMEs. Sustainability 2019, 11, 3714.

13. Lin, F.; Lin, S.-W.; Lu, W.-M. Sustainability Assessment of Taiwan's Semiconductor Industry: A New Hybrid Model Using Combined Analytic Hierarchy Process and Two-Stage Additive Network Data Envelopment Analysis. Sustainability 2018, 10, 4070.

\section{References}

1. Schumpeter, J.A. The Theory of Economic Development: An Inquiry Into Profits, Capital, Credit, Interest, and the Business Cycle. In Transaction Books; Harvard University Press: Cambridge, MA, USA, 1934.

2. Arend, R.J. Entrepreneurship and dynamic capabilities: How firm age and size affect the 'capability enhancement-SME performance' relationship. Small Bus. Econ. 2014, 42, 33-57. [CrossRef] 
3. Camisón-Zornoza, C.; Lapiedra-Alcamí, R.; Segarra-Ciprés, M.; Boronat-Navarro, M.; Camisn-Zornoza, C.; Lapiedra-Alcam, R.; Segarra-Ciprs, M. A Meta-analysis of Innovation and Organizational Size. Organ. Stud. 2004, 25, 331-361. [CrossRef]

4. Damanpour, F. Organizational Size and Innovation. Organ. Stud. 1992, 13, 375-402. [CrossRef]

5. Messeni Petruzzelli, A.; Ardito, L.; Savino, T. Maturity of knowledge inputs and innovation value: The moderating effect of firm age and size. J. Bus. Res. 2018, 86, 190-201. [CrossRef]

6. Damanpour, F. An Integration of Research Findings of Effects of Firm Size and Market Competition on Product and Process Innovations. Br. J. Manag. 2010, 21, 996-1010. [CrossRef]

7. Leal-Rodríguez, A.L.; Eldridge, S.; Roldán, J.L.; Leal-Millán, A.G.; Ortega-Gutiérrez, J. Organizational unlearning, innovation outcomes, and performance: The moderating effect of firm size. J. Bus. Res. 2015, 68, 803-809. [CrossRef]

(C) 2019 by the authors. Licensee MDPI, Basel, Switzerland. This article is an open access article distributed under the terms and conditions of the Creative Commons Attribution (CC BY) license (http://creativecommons.org/licenses/by/4.0/). 